\title{
ATTENUATION OF CARBON TETRACHLORIDE AND ETHANOL-INDUCED HEPATIC FIBROSIS IN RATS BY CALLIGONUM COMOSUM SHOOT EXTRACT
}

\author{
SHERIEN KAMAL HASSAN*, AMRIA MAMDOUH MOUSA, NERMIN MOHAMMED EL-SAMMAD
}

Department of Biochemistry, National Research Centre, Cairo, Egypt. Email: sherien.kamal.hassan@gmail.com

Received: 26 May 2016, Revised and Accepted: 07 December 2016

\section{ABSTRACT}

Objective: This study was designed to evaluate the hepatoprotective and antioxidant effects of methanolic extract of Calligonum comosum (C. comosum) shoots on the hepatic fibrosis induced by carbon tetrachloride and ethanol $\left(\mathrm{CCl}_{4} /\right.$ ethanol) in rats.

Methods: A liver fibrosis was induced in Sprague Dawley rats by oral administration of $\mathrm{CCl}_{4}(1 \mathrm{ml} / \mathrm{kg}$ body weight, twice weekly for 10 weeks) along with ethanol ( $10 \%$ in drinking water 1 week before $\mathrm{CCl}_{4}$ administration and throughout the experiment). Rats were pretreated with $\mathrm{C}$. comosum extract (daily, orally at a dose of $50 \mathrm{mg} / \mathrm{kg}$ body weight 1 week before $\mathrm{CCl}_{4}$ administration). At the end of the experiment, serum, and liver samples were subjected to biochemical investigations. In addition, liver and kidney tissues were evaluated for histopathological changes.

Results: $C$. comosum extract pretreatment significantly reduced $\mathrm{CCl}_{4}$ - induced elevation in serum levels of aspartate aminotransaminase, alanine aminotransaminase, alkaline phosphatase, total bilirubin, urea, creatinine, and significantly elevated serum contents of total protein and albumin, as well as an improvement in hepatic protein content, albumin/globulin ratio, body weight and relative liver and kidney weights. C. comosum extract also significantly increased the hepatic levels of glucose-6-phosphatase, glutathione peroxidase, glutathione-S-transferase, catalase, superoxide dismutase, and glutathione with significant decrease in the contents of malondialdehyde and protein carbonyl. In addition, downregulation in expression of the fibrotic marker matrix metalloproteinase- 2 was observed. $C$. comosum extract also ameliorated histopathological changes of $\mathrm{CCl}_{4} /$ ethanol group which further evidenced the biochemical findings.

Conclusion: Our results confirmed that the methanolic extract of $C$. comosum shoots effectively protect against $\mathrm{CCl}_{4} /$ ethanol-induced liver fibrosis, through its antioxidant property.

Keywords: Calligonum comosum, Hepatic fibrosis, Carbon tetrachloride, Hepatoprotective effect, Antioxidants, Matrix metalloproteinase-2.

(C) 2017 The Authors. Published by Innovare Academic Sciences Pvt Ltd. This is an open access article under the CC BY license (http://creativecommons. org/licenses/by/4. 0/) DOI: http://dx.doi.org/10.22159/ajpcr.2017.v10i3.13105

\section{INTRODUCTION}

Hepatic fibrosis is an early finding in most chronic liver diseases and its progression causes liver cirrhosis, and finally, leads to organ failure and death [1]. Cirrhosis is one of the major diseases affecting millions of people worldwide and is the third most common cause of death among people aged 45-65 years [2].

Carbon tetrachloride $\left(\mathrm{CCl}_{4}\right)$ is an industrial solvent and one of the most potent hepatotoxins, which is most widely used for experimental induction of liver fibrosis and for screening of hepatoprotective agents [3]. Its hepatotoxic effect is thought to be initiated through its reductive dehalogenation by cytochrome $\mathrm{P} 450$ to the highly reactive trichloromethyl radical $\left({ }^{+} \mathrm{CCl}_{3}\right)$, which is subsequently converted into a trichloromethyl peroxyl radical $\left({ }^{+} \mathrm{OOCCl}_{3}\right)[4,5]$. These free radicals initiate the process of lipid peroxidation, which is the most important mechanism in the pathogenesis of hepatocellular damage and enhances production of fibrotic tissue [6]

According to Wang et al. [7], reactive oxygen species (ROS) and oxidative stress that have been implicated in the process of liver fibrogenesis, suggested a possible role for antioxidants in preventing or reducing chronic liver damage and fibrosis. There is a resurgence of interest in natural remedies for treatment and/or protection against free radicals causing various ailments including hepatopathy $[8,9]$.

The genus Calligonum belongs to the family Polygonaceae, which comprises about 80 species and is found in many countries such as Northern Africa, Western Asia, and Southern Europe. Calligonum comosum L'Herit, an Egyptian desert plant, has a reputation in folk medicine as a stimulant, tonic, and astringent [10]. Furthermore, it is used to treat toothache and ophthalmic and stomach problems [11]. Pharmacological and toxicological studies have demonstrated various biological effects of C. comosum including antibacterial [12] antiinflammatory, antinociceptive, antipyretic, gastroprotective [13], and antihypertension [11] effects. Furthermore, C. comosum exhibited anticancer activities in mice inoculated with Ehrlich ascites carcinoma cells [14] and dopaminergic effects on haloperidol-induced neuro and hepatotoxicities [15], and finally exhibited significant chemopreventive effects against diethylnitrosamine-induced hepatocarcinogenesis in rats [16]. These biological properties may be attributed to $C$. comosum antioxidative activity, where previous phytochemical analysis of C. comosum aerial parts showed that it is rich in polyphenolic compounds, which are responsible for its antioxidant activity [15].

However, little chemical studies were reported on C. comosum shoots, and to our knowledge, no reports have recorded the effect of C. comosum shoots on hepatic fibrosis. Therefore, the objective of this study is to investigate its hepatoprotective and antioxidant effects on $\mathrm{CCl}_{4} /$ ethanol-induced liver fibrosis.

\section{METHODS}

Chemicals

Streptomycin sulfate was obtained from Pvt. Ltd., (India). 2,4-dinitrophenylhydrazine was obtained from S D Fine-Chem. Ltd. (India). Guanidine hydrochloride, malonaldehydebis (dimethyl acetal), reduced glutathione (GSH), 5,5' dithiobis-2-nitrobenzoic acid, 1-cholro 
2,4-dinitrobenzene, maleic acid, glucose-6-phosphate, gelatin, N,N,N',N`tetramethylethylenediamine, bisacrylamide, and trizma were purchased from Sigma-Aldrich (St. Louis, MO, USA), Metaphosphoric acid and nitrobluetetrazolium (Fluka, Switzerland) and pyrogallol (Merck, Germany). All other chemicals used were of analytical reagent grade.

\section{Plant material}

The shoots of C. comosum were collected in April 2012 from international desert road, Dammita, Egypt, authenticated by Dr. Ahmed Mohamed Abd El-Gawad, Science faculty, Mansoura University, Egypt. A voucher sample (No: CP-012-129) was deposited at the herbarium of the National Research Centre.

\section{Extraction and isolation}

Shoots of $C$. comosum were shade-dried ( $800 \mathrm{~g}$ ), macerated in $70 \%$ methanol at room temperature, filtered and dried under vacuum to yield dark black gum $(58 \mathrm{~g})$. The dry alcoholic extract was dissolved in distilled water then successively fractionated with n-hexane, methylene chloride, and methanol. The methanol extract ( $25 \mathrm{~g}$ ) was subjected to polyamide $6 \mathrm{~S}$ column chromatography using a water/methanol step gradient afforded 30 fractions that were finally collected to five major fractions C1-C5. Fractions C1-C5 were subjected to different chromatographic techniques afforded 7 pure compounds (1-7). Fraction C5 was subjected to Sephadex LH-20 column eluted with methanol/ $\mathrm{H}_{2} \mathrm{O}(8: 2)$ afforded compounds 1 and 2. Fractions C3 and C4 were separately subjected to preparative paper chromatography eluted by $15 \%$ acetic acid then rapid purification on Sephadex LH-20 afforded compounds 3 and 4. Fraction C2 was subjected to Sephadex LH-20 eluted by methanol afforded compounds 5, 6 and 7. The identification of the isolated compounds was occurred using different spectroscopic analysis. Nuclear magnetic resonance spectroscopy was carried out using a JEOL-EX $500 \mathrm{MHz}$ (JEOL Ltd, Japan) in dimethyl sulfoxide-d6 solvent. Electrospray ionization source spectra were obtained on JEOL JMS-AX 500 (JEOL Ltd, Japan). Ultraviolet (UV) spectra were obtained by OMM 7070E-UV 240 spectrophotometer (Shimadzu, USA).

\section{Phytochemical screening}

The methanol extract of $C$. comosum was screened for the presence of various phytoconstituents as described by Dawang and Datup [17] and Mythili and Ravindhran [18].

1,1-Diphenyl-2-picryl-hydrazyl (DPPH) radical scavenging assay The antioxidant activity of methanol extract and major (C1-C5) five fractions were measured in terms of radical-scavenging ability, using the stable radical DPPH free radical scavenging activity method with some modification [19]. A volume of $50 \mu \mathrm{l}$ of a methanolic extract or the major five column fractions C1-C5 solutions of determined concentrations were put into a cuvette. $2 \mathrm{ml}$ of $6 \times 10^{-5} \mathrm{~mol} / \mathrm{L}$ methanolic solution of DPPH was added. The mixtures were well shaken in a vortex for 1 minute and then placed in a dark room. The decrease in absorbance at $517 \mathrm{~nm}$ was determined with Jenway 6315 spectrophotometer (Bibby Scientific Ltd, UK) after $1 \mathrm{hr}$ for all samples. The absorbance of the radical without extract was used as control. The amount of sample necessary to decrease the absorbance of DPPH by $50 \%\left(\mathrm{IC}_{50}\right)$ was calculated graphically. The inhibition percentage of the DPPH radical was calculated according to the formula:

$$
\begin{aligned}
& \text { DPPH inhibition } \% \\
& =\frac{(\text { Control absorbance }- \text { Sample absorbance })}{(\text { Control absorbance })} \times 100
\end{aligned}
$$

\section{Acute toxicity study}

The mean lethal dose $\left(\mathrm{LD}_{50}\right)$ of the methanolic extract of $C$. comosum shoots was determined in rats (weighing 120-170 g) using the method described by Chinedu et al. [20].

\section{Animals and experimental design}

Female Sprague Dawley rats weighing 120-170 g were obtained from the Animal House, National Research Centre, Egypt. Animals were housed under standard laboratory conditions of light (12:12 hrs day-night cycle), temperature $\left(21 \pm 2^{\circ} \mathrm{C}\right)$ and relative humidity $(55 \pm 5 \%)$ and were fed with standard laboratory diet and allowed to drink water ad libitum. All animal procedures were conducted in accordance with legal requirements appropriate to the species (Guiding Principles for the Care and Use of Laboratory Animals, NIH publication 85-23, revised in 1985) and were approved by the Ethics Committee of the National Research Centre.

Rats were divided randomly into four groups (six rats in each group):

Group I (control group): Rats were orally administrated with olive oil (1 ml/kg body weight) as vehicle twice weekly for 10 weeks.

Group II (C. comosum exract group): Rats received C. comosum extract as a suspension of water by oral gavage at a dose of $50 \mathrm{mg} / \mathrm{kg} \mathrm{b}$. w., daily for 10 weeks.

Group III ( $\mathrm{CCl}_{4} /$ ethanol group): Rats were treated with intragastric injections of $\mathrm{CCl}_{4}$ (diluted 1:1, v/v in olive oil) twice weekly for 10 weeks at dose of $1 \mathrm{ml} / \mathrm{kg}$ body weight. They also received $10 \%$ ethanol added to their drinking water ad libitum before $\mathrm{CCl}_{4}$ injection by 1 week and continued throughout the experimental period [21].

Group IV $\left(\mathrm{CCl}_{4} /\right.$ ethanol $+C$. comosum extract group): Rats were treated with $C$. comosum extract preceding $\mathrm{CCl}_{4}$ administration by 1 week and continued until the end of the experiment. During the experimental period, animals were weighed once weekly to monitor changes in weight and to adjust the dosages of $C$. comosum extract and $\mathrm{CCl}_{4}$ accordingly.

On the termination day, overnight fasted rats were sacrificed by cervical dislocation under ether anesthesia, blood was collected, and serum was separated by centrifugation at $3000 \mathrm{rpm}$ for 10 minutes at $4^{\circ} \mathrm{C}$ and stored at $-20^{\circ} \mathrm{C}$ until analysis. Liver and kidney from all animal groups were excised immediately, rinsed with ice-cold saline, dried and weighed. Kidney and part of liver were fixed by immersion in $10 \%$ neutral formaldehyde for histopathological investigations. The remaining of the liver was divided into two parts. The two parts were homogenized in normal saline and in $0.1 \mathrm{M}$ phosphate buffer $(\mathrm{pH} 7.4)$ to give $10 \%(\mathrm{w} / \mathrm{v})$ homogenate using TM125 homogenizer (Omni International, USA). The homogenate was centrifuged at $3000 \mathrm{rpm}$ for 15 minutes at $4^{\circ} \mathrm{C}$. The supernatant was used for assessment of various biochemical determinations.

\section{Serum biochemical analysis}

Serum alkaline phosphatase (ALP), total bilirubin, total protein, albumin, urea, and creatinine were assayed using kits supplied by (Reactivos GPL, Barcelona, Spain). Serum aspartate transaminase (AST) and alanine transaminase (ALT) were assayed using (Biorexfars Diagnostic Limited, UK) kits.

\section{Hepatic biochemical analysis}

Saline homogenate was used to estimate glucose-6-phosphatase (G-6-pase) activity according to Swanson assay [22]. Phosphate buffer homogenate was used to estimate protein carbonyl [23] and malondialdehyde (MDA) levels [24] as oxidative stress biomarkers. Furthermore, phosphate buffer was used to estimate antioxidant parameters such as, GSH, glutathione peroxidase (GSH-Px), glutathioneS-transferase (GST), catalase (CAT), and superoxide dismutase (SOD) which were assayed according to the methods of Beutler et al. [25], Necheles et al. [26], Habig et al. [27], Aebi [28], and Minami and Yoshikawa [29], respectively. In addition to this, total protein was estimated according to Lowry et al. [30] to calculate the protein content in the hepatic samples.

\section{Matrix metalloproteinase (MMP) zymography}

MMP-2 activity was estimated by gelatin zymography as described by Toth et al. [31]. $10 \mu \mathrm{g}$ of liver tissue protein was separated by a $7.5 \%$ SDS - polyacrylamide gel electrophoresis using CVS10DSYS-CU miniprotein electrophoresis (Cleaver Scientific Ltd, UK) containing $0.2 \%$ gelatin. After electrophoresis, gel was washed twice for 30 minutes in $2.5 \%$ Triton X-100 to remove the SDS, then washed in reaction buffer 
containing $50 \mathrm{mM}$ Tris- $\mathrm{HCl}$, pH 7.5, $5 \mathrm{mM} \mathrm{CaCl}_{2}, 1 \mu \mathrm{M} \mathrm{ZnCl}_{2}$. The gels were incubated in a fresh reaction buffer at $37^{\circ} \mathrm{C}$ overnight. Gelatinolytic activity was visualized by staining the gels with $0.5 \%$ Coomassie blue R-250, destained with methanol-acetic acid water (50:10:40 v/v) until clear bands against dark background appeared. The intensity of the bands was assayed by Gel Doc ${ }^{\mathrm{TM}}$ XRT molecular imaging system (BioRad, USA).

\section{Histopathological examination}

Liver and kidney specimens, fixed in formalin, were processed in paraffin wax then cut into six-micrometer sections. Kidney sections were stained with hematoxilin and eosin (H \& E). Liver sections were stained with H \& E and Van Gieson's (VG) staining to visualize fibrosis [32]. The hepatic fibrosis was scored according to the Knodell index, as follows: (0) absence of fibrosis; (1) portal fibrous; (2) fibrous portal expansion; (3) bridging fibrosis (portal-portal or portal-central linkage); (4) cirrhosis. Quantitative measurements were achieved using image analyzer (Leica Qwin 500 image) in Image Analyzer Unit, Pathology Department, National Research Centre. To measure the collagen area in slides stained with VG stain, the areas of reactivity were masked and measured in 10 small measuring frames in each specimen.

\section{Statistical analysis}

Results are expressed as means \pm standard error of the mean. Statistical analysis was performed by one-way analysis of variance for multiple comparisons (SPSS, version 14.0) followed by least significant difference test to detect differences between groups. The differences were considered statistically significant at $p<0.05$.

\section{RESULTS}

\section{Phytochemical screening}

Phytochemical screening of the C. comosum methanolic extract indicated the presence of flavonoids, alkaloids, tannins, steroids, phenols, terpenoids, and essential oil

\section{Chemical characterization of $C$. comosum extract}

The chemical characterization of the methanol extract afforded; quercetin (1), kaempferol (2), kaempferol 3-0- $\alpha$-lrhamnopyranoside (3), quercetin 3-0- $\alpha$-l-rhamnopyranoside (4) in addition to three phenolic acids: Gallic acid (5), methyl gallate (6), and p-comaric acid (7). Compounds 1, 2, 5, 6 and 7 were reported for the first time from C. comosum. All compounds were identified according to comparison of their spectral data with those reported previously.

\section{DPPH radical scavenging activity of $C$. comosum extract and column} fractions

Methanol extract of $C$. comosum showed the strongest scavenging activity followed by fraction $\mathrm{C} 2$ with $\mathrm{IC}_{50} 68.2 \pm 0.322$ and $80.6 \pm 0.25$, respectively (Fig. 1). The significant antioxidant activity of all tested fractions may be attributed to the presence of flavonoids and phenolic acids.

Effect of $C$. comosum extract on body weight, liver and kidney weights and relative weights of liver and kidney

The average body weight of both control and $C$. comosum extract groups increased regularly till the end of the experiment. However, there was an obvious decrease in the weight of $\mathrm{CCl}_{4} /$ ethanol group after week 6 up to the last week as shown in Fig. 2, with 17\% increase in the final mean body weight in $\mathrm{CCl}_{4}$ /ethanol group comparing to $50 \%$ increase in the control group as shown in Table 1. On contrary, pretreatment with C. comosum extract in Group IV caused gradual increase in the body weight till week 6 , then body weight was almost stable till the end of the experiment with $28 \%$ increase in the final mean body weight as shown in Table 1.

As shown in Table 1, administration of $\mathrm{CCl}_{4} /$ ethanol significantly elevated liver and kidney weight as compared to control group, producing $64 \%$ and $48 \%$ increase in relative liver weight (RLW) and relative kidney weight (RKW), respectively. C. comosum extract pretreatment significantly reduced liver and kidney weight and their relative weights (Table 1 )

\section{Effect of $C$. comosum extract on hepatic and renal functions}

As shown in Table 2, $\mathrm{CCl}_{4}$ /ethanol markedly increased serum levels of AST (3.71-fold), ALT (14.33-fold), ALP (6.5-fold) and total bilirubin (2.3-fold) when compared to the control group. On the other hand, levels of serum protein, albumin and $\mathrm{A} / \mathrm{G}$ ratio in $\mathrm{CCl}_{4}$ /ethanol group were significantly lower than that in the control group by $21.8 \%, 40.9 \%$ and $32.3 \%$, respectively. Moreover, $\mathrm{CCl}_{4}$ /ethanol treatment significantly increased the serum levels of urea $(58.7 \%)$ and creatinine (2.4-fold) as compared with the control group. C. comosum extract significantly improved all the $\mathrm{CCl}_{4}$ - induced alterations in both hepatic and renal injury markers. C. comosum $+\mathrm{CCl}_{4} /$ ethanol group recorded reduction by $50,60,53,23,20$ and $40 \%$ for AST, ALT, ALP, total bilirubin, urea and creatinine, respectively, comparing to $\mathrm{CCl}_{4}$ /ethanol group. Furthermore, serum protein, albumin and $\mathrm{A} / \mathrm{G}$ ratio levels were increased by 13,32 and $22 \%$, respectively, relative to $\mathrm{CCl}_{4}$ /ethanol group.

\section{Effect of $C$. comosum extract on G-6-pase and hepatic protein} $\mathrm{CCl}_{4} /$ ethanol-induced rats recorded a significant decrease in G-6-pase by $74 \%$ compared to control (Fig. 3). Contradictory, pretreatment with C. comosum extract in Group IV recorded increase in G-6-pase activity by $42 \%$ compared to $\mathrm{CCl}_{4} /$ ethanol group. Moreover, $\mathrm{CCl}_{4} /$ ethanol treatment in Group III rats resulted in a significant decrease in hepatic protein content by $40 \%$ compared to the control group. Pretreatment with $C$. comosum extract attenuated such decrease of hepatic protein by $21.5 \%$ (Table 3 ).

\section{Effect of $C$. comosum extract on oxidative damage biomarkers}

The levels of protein carbonyl (marker of protein oxidation) and MDA (marker of lipid peroxidation) in $\mathrm{CCl}_{4} /$ ethanol group have significantly increased by 2.4- and 3.6-fold, respectively, as compared to control level. On the other hand, the treatment of $\mathrm{CCl}_{4} /$ ethanol-induced rats with $C$. comosum extract significantly reduced the level of protein carbonyl (33\%) and MDA (46\%) in comparing to $\mathrm{CCl}_{4} /$ ethanol group (Table 3)

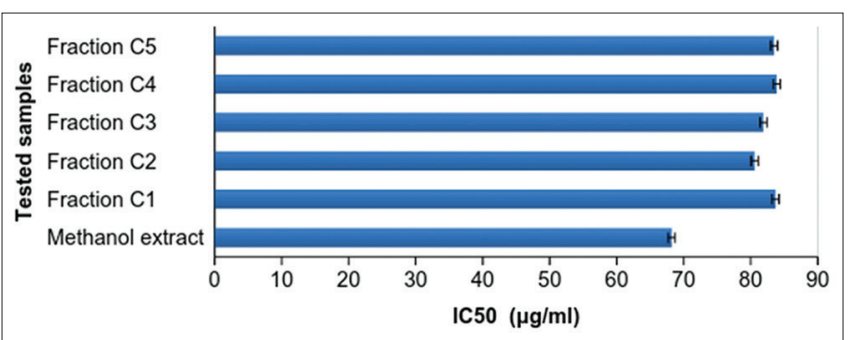

Fig. 1: DPPH radical scavenging activity of $C$.comosum extract and column fractions

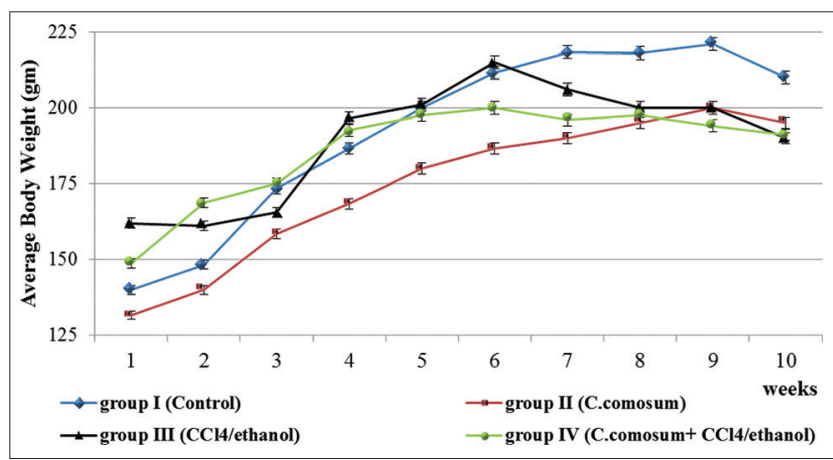

Fig. 2: Comparison of weekly body weight change between groups over the experimental period. Values are expressed as mean \pm SEM of six rats in each group 
Table 1: Effect of $C$. comosum extract on body weight, liver and kidney weights and relative weight of liver and kidney

\begin{tabular}{|c|c|c|c|c|}
\hline Groups parameters & (I) Control & (II) C. comosum & (III) $\mathrm{CCl}_{4}$ /ethanol & (IV) C. comosum $+\mathrm{CCl}_{4} /$ ethanol \\
\hline Body weight gained (g) & $69.54 \pm 10.46$ & $63.34 \pm 7.14^{b}$ & $27.89 \pm 8.02^{\mathrm{a}}$ & $41.09 \pm 9.78^{\mathrm{a}}$ \\
\hline Liver weight $(\mathrm{g})$ & $5.74 \pm 0.22$ & $4.91 \pm 0.39^{\mathrm{b}}$ & $8.95 \pm 0.45^{\mathrm{a}}$ & $6.28 \pm 0.29^{b}$ \\
\hline RLW & $2.86 \pm 0.11$ & $2.69 \pm 0.13^{b}$ & $4.68 \pm 0.14^{\mathrm{a}}$ & $3.31 \pm 0.17^{\mathrm{ab}}$ \\
\hline Kidney weight (g) & $1.16 \pm 0.04$ & $1.09 \pm 0.04^{\mathrm{b}}$ & $1.65 \pm 0.06^{\mathrm{a}}$ & $1.23 \pm 0.01^{\mathrm{b}}$ \\
\hline RKW & $0.58 \pm 0.02$ & $0.60 \pm 0.01^{b}$ & $0.86 \pm 0.05^{\mathrm{a}}$ & $0.64 \pm 0.02^{b}$ \\
\hline
\end{tabular}

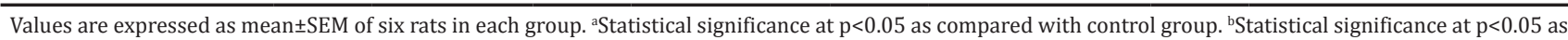
compared with $\mathrm{CCl}_{4}$ /ethanol group. C. comosum: Calligonum comosum, RLW: Relative liver weight, RKW: Relative kidney weight

Table 2: Effect of C. comosum extract on hepatic and renal functions

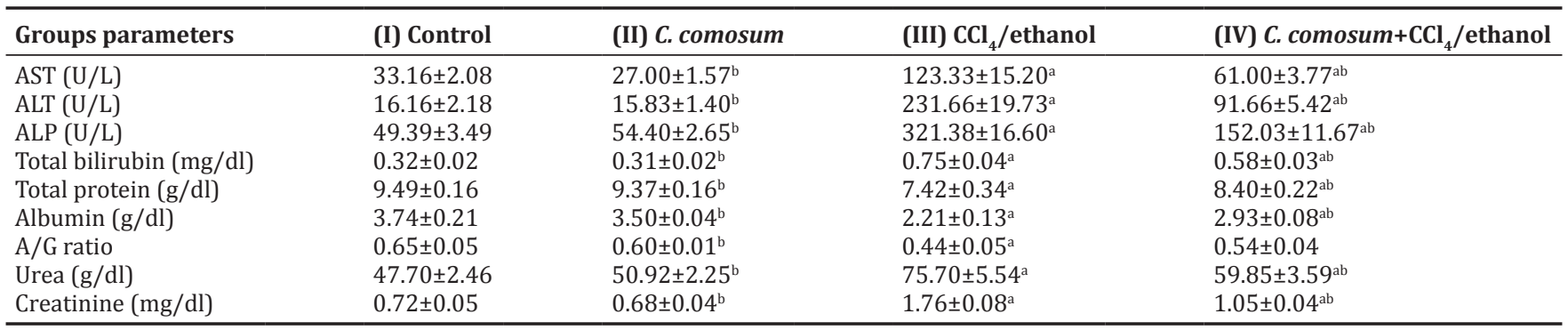

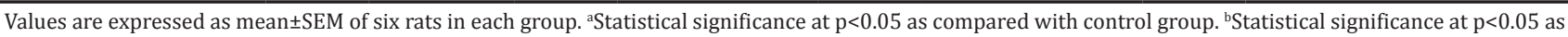
compared with $\mathrm{CCl}_{4}$ /ethanol group. AST: Aspartate transaminase, ALT: Alanine transaminase, ALP: Alkaline phosphatase. C. comosum: Calligonum comosum

Table 3: Effect of $C$. comosum extract on oxidative damage biomarkers

\begin{tabular}{llll}
\hline Groups & Total protein (mg/g tissue) & Protein carbonyl (nmol/mg protein) & MDA (nmol/mg protein) \\
\hline (I) Control & $280.26 \pm 25.44$ & $0.53 \pm 0.06$ & $4.35 \pm 0.41$ \\
(II) C. comosum & $284.91 \pm 26.03^{\mathrm{b}}$ & $0.49 \pm 0.47^{\mathrm{b}}$ & $4.86 \pm 0.38^{\mathrm{b}}$ \\
(III) CCl $/$ ethanol & $168.41 \pm 8.8^{\mathrm{a}}$ & $1.28 \pm 0.1^{\mathrm{a}}$ & $15.88 \pm 1.7^{\mathrm{a}}$ \\
(IV) C. comosum+CCl$_{4} /$ ethanol & $220.01 \pm 9.82^{\mathrm{a}}$ & $0.86 \pm 0.09^{\mathrm{ab}}$ & $8.65 \pm 0.82^{\mathrm{ab}}$ \\
\hline
\end{tabular}

Values are expressed as mean \pm SEM of six rats in each group. aStatistical significance at $\mathrm{p}<0.05$ as compared with control group. ${ }^{\mathrm{b}}$ Statistical significance at $\mathrm{p}<0.05$ as compared with $\mathrm{CCl}_{4}$ /ethanol group. MDA: Malondialdehyde. C. comosum: Calligonum comosum

\section{Effect of $C$. comosum extract on hepatic antioxidants}

$\mathrm{CCl}_{4}$ /ethanol treatment markedly decreased the content of liver GSH as well as antioxidant enzymes. As shown in Fig. 4, $\mathrm{CCl}_{4} /$ ethanol group recorded a significant decrease in the levels of hepatic GSH (78\%), GSH-Px (40\%), GST (38\%), CAT (45\%), and SOD (47\%) when compared with control group. Treatment with C. comosum extract in Group IV significantly improved GSH, GSH-Px, GST and SOD by $34,21,20$ and $22 \%$, respectively, compared to $\mathrm{CCl}_{4} /$ ethanol group. Interestingly, C. comosum extract treatment restored CAT activity to near control level.

\section{Effect of $C$. comosum extract on MMPs activity}

As shown in Fig. 5a, gelatin zymography revealed that various rat groups expressed only the latent form of MMP- 2 at about $72 \mathrm{kDa}$. Control rats expressed the least MMP- 2 activity. Treatment with $\mathrm{CCl}_{4} /$ ethanol resulted in a clearly increased MMP-2 expression in Group III control, while administration of $C$. comosum extract tended to reduce such expression in C. comosum extract $+\mathrm{CCl}_{4} /$ ethanol group. Furthermore, densitometric analysis of zymography bands revealed a significant increase (4.16-fold) in MMP-2 gelatinolytic activity of $\mathrm{CCl}_{4} /$ ethanol group compared to controls. Pretreatment with $C$. comosum extract produced $34 \%$ reduction in activity of Group IV in comparison to $\mathrm{CCl}_{4} /$ ethanol group (Fig. $5 \mathrm{~b}$ ).

\section{Effect of $C$. comosum extract on liver morphology}

Morphological observations showed that liver of $\mathrm{CCl}_{4} /$ ethanol injured rats lost the normal reddish-brown color and changed to more or less light brown. In addition, the liver was enlarged in size and lost its smoothly surface. Moreover, pale yellow spots and large patches were scattered on the liver surface. These morphological changes were reversed to normal by pretreatment with C. comosum extract (Fig. 6).

\section{Histopathological examination of liver}

In case of liver $\mathrm{H} \& \mathrm{E}$ staining, microscopic investigation of liver sections of control and C. comosum extract groups showed normal architecture of hepatic lobules and hepatocytes (Fig. 7a and b). However, rats given $\mathrm{CCl}_{4} /$ ethanol showed dissection nodules and fibrous septa with effacement of the lobular architecture (Fig. 7c) and revealed fatty degeneration which forms signet ring cells (Fig. 7d). On the other hand, liver sections of $C$. comosum extract $+\mathrm{CCl}_{4} /$ ethanol group showed in some cases normal architecture of hepatic lobules and hepatocytes (Fig. 7e) and in the other cases showed necrotic hepatocytes and fatty changes (Fig. 7f).

In case of liver VG staining, the control and C. comosum extract groups showed a normal distribution of collagen deposition (Fig. 8a, b and f). However, rats received $\mathrm{CCl}_{4} /$ ethanol the liver exhibited a progress increase in collagen accumulation, with periportal fibrosis characterized by portal-portal fibrous septa surrounding the hepatic lobules which resulted in distorted tissue architecture (Fig. 8c). On the other hand, C. comosum extract pretreatment caused septal collagen deposition to disappear or to become thinner (Fig. 8d and e). The quantitative histological analysis presented in Table 4, revealed that the degree of liver fibrosis in $\mathrm{CCl}_{4}$ /ethanol group ranged from moderate fibrosis to cirrhosis and collagen levels were significantly increased as compared with control rats. Alternatively, C. comosum extract showed marked improvement in the fibrosis degree and significant decrease in collagen levels as compared to $\mathrm{CCl}_{4} /$ ethanol injured group.

\section{Histopathological examination of kidney}

The kidney sections from the control and $C$. comosum extract groups showed normal architecture of glomeruli, tubules, and capillaries 


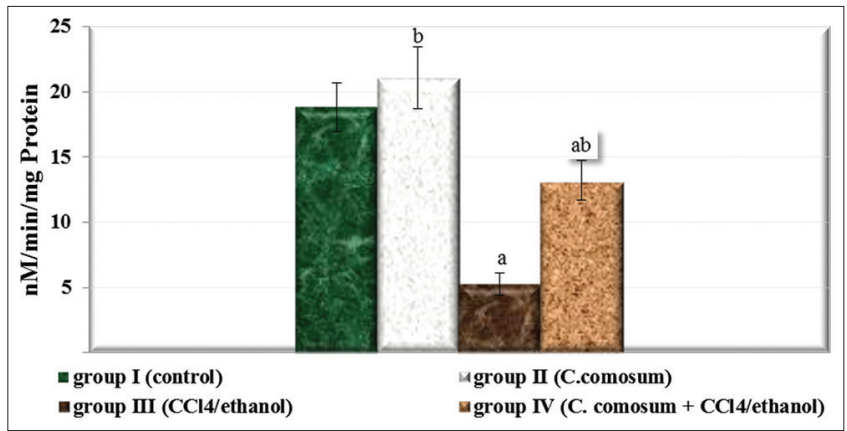

Fig. 3: Effect of $C$. comosum extract on hepatic G-6-pase enzyme in $\mathrm{CCl}_{4} /$ ethanol-treated rats. Values are expressed as mean $\pm \mathrm{SEM}$ of six rats in each group. ${ }^{\mathrm{a}} \mathrm{p}<\mathbf{0 . 0 5}$ is significantly different from control group; ${ }^{\mathrm{b}} \mathbf{p}<0.05$ is significantly different from $\mathrm{CCl}_{4} /$ ethanol group

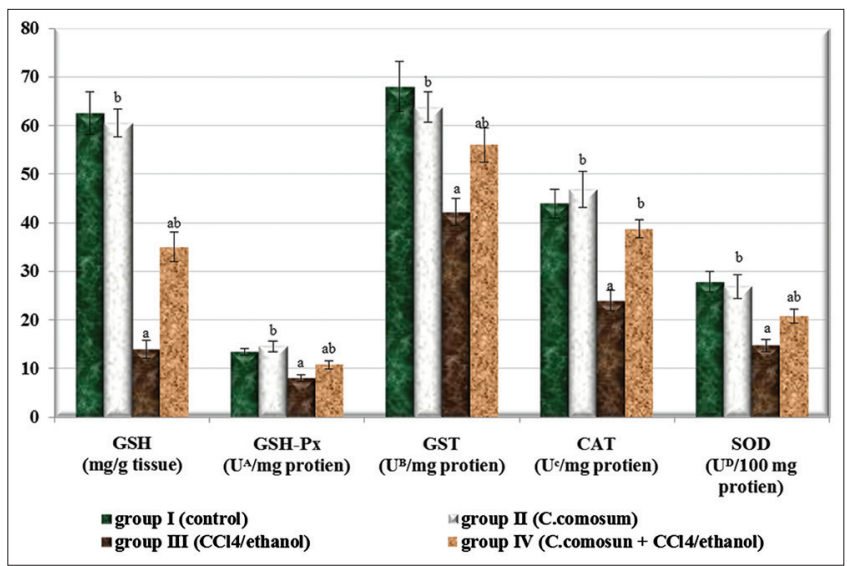

Fig. 4: Effect of $C$. comosum extract on antioxidant levels in $\mathrm{CCl}_{4}$ /ethanol-treated rats. Values are expressed as mean \pm SEM of six rats in each group. ${ }^{a} p<0.05$ is significantly different from control group; ${ }^{\mathrm{b}} \mathbf{p}<0.05$ is significantly different from $\mathrm{CCl}_{4} /$ ethanol group. $\mathrm{U}^{\mathrm{A}}: \mu \mathrm{g}$ of GSH oxidized/minute/mg protein, $U^{\mathrm{B}}$ : nmoles of 1-cholro 2,4-dinitrobenzene-GSH conjugate formed $/ \mathrm{minute} / \mathrm{mg}$ protein, $U^{C}$ : $\mu$ mole of $\mathrm{H}_{2} \mathbf{O}_{2}$ decomposed $/$ minute $/ \mathrm{mg}$ protein, $\mathrm{U}^{\mathrm{D}} \mathbf{5} \mathbf{5 0 \%}$ inhibition of nitroblue tetrazolium reduction for $100 \mathrm{mg}$ protein

(Fig. 9a and b). Conversely, $\mathrm{CCl}_{4}$ administration caused prominent histopathological damage in the kidney. The $\mathrm{CCl}_{4} /$ ethanol injured rats showed glomerular atrophy, tubular degeneration, epithelium necrosis of the tubules, interstitial edema, and congestion in capillary loops (Fig. 9c). While pretreatment with C. comosum extract preserved normal histological form of the kidney (Fig. 9d). The histopathological changes were graded and summarized in Table 5.

\section{DISCUSSION}

Hepatic fibrosis is a pathological progression associated with abnormal proliferation of connective tissue in response to chronically damaged liver tissue. It is often caused by hepatitis, alcoholism and other potentially damaging toxins [33,34]. Hepatic cirrhosis would be developed if hepatic fibrosis treatment was delayed [35]. Chronic alcohol consumption is a major risk factor for development of hepatic fibrosis [36]. Administration of ethanol with repetitive $\mathrm{CCl}_{4}$ ingestion could be more effective in maintaining the fibrotic pattern because ethanol increases activation of cytochrome P450 [37], resulting in greater liver damage than with either agent alone [38]. Various plant extracts have been widely applied to treat chronic liver diseases, including chronic hepatic inflammation and fibrosis [39].

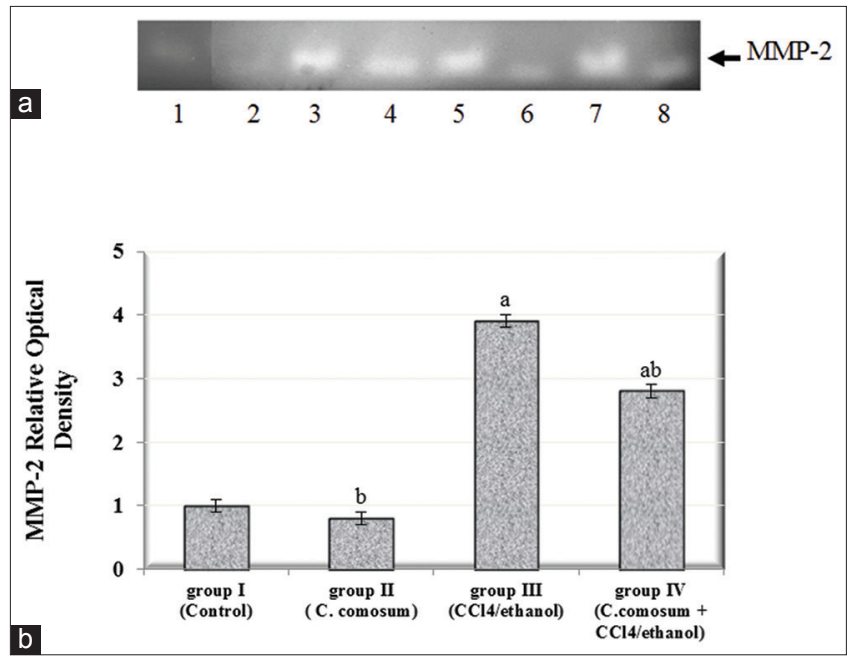

Fig. 5: Gelatin zymogram of liver specimens from different animal groups. (a): Expression of $72 \mathrm{kDa}$ MMP-2 in equal protein quantities of hepatic homogenates from control group (lane 1), C. comosum extract group (lane 2 ), $\mathrm{CCl}_{4} /$ ethanol group (lane 3-5), and C. comosum extract $+\mathrm{CCl}_{4} /$ ethanol group (lane 6-8). (b): Densitometric analysis of bands detected in gelatin zymograms. The bar graph shows averages of band intensity of MMP-2 (mean \pm SEM). ${ }^{\mathrm{a} p}<0.05$ is significantly different from control group; ${ }^{b} \mathbf{p}<0.05$ is significantly different from $\mathrm{CCl}_{4} /$ ethanol group

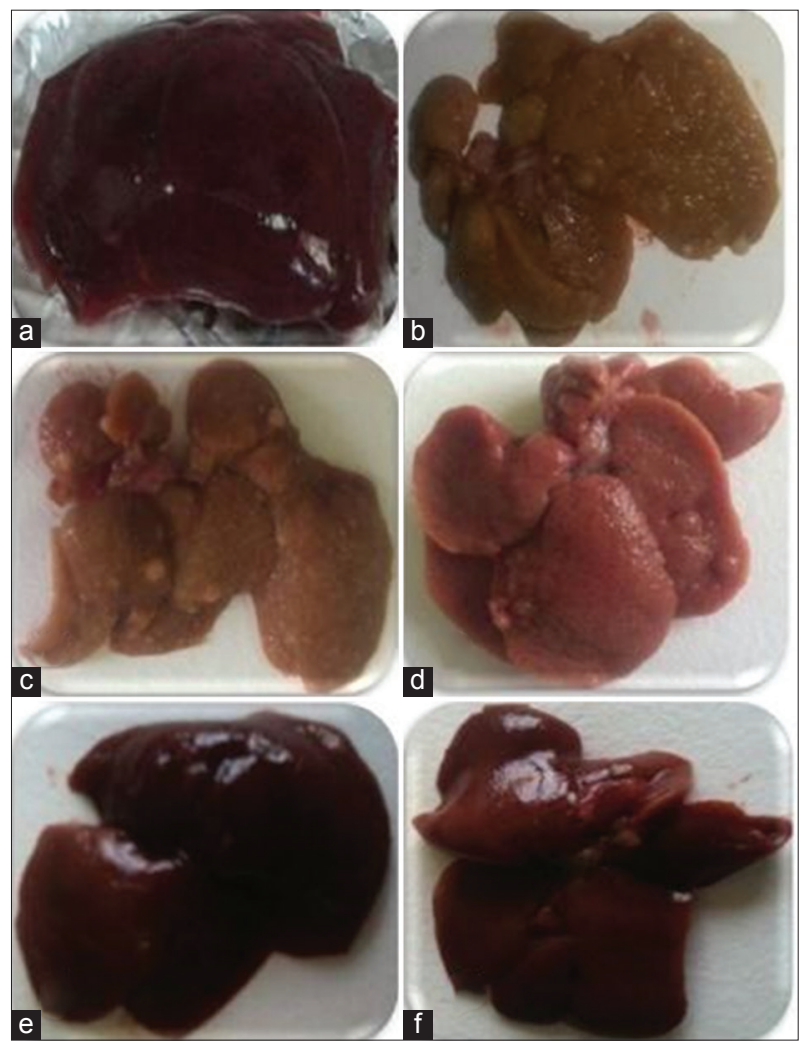

Fig. 6: Morphological structure of normal and $\mathrm{CCl}_{4} /$ ethanol treated livers. (a) Normal liver, (b-d) $\mathrm{CCl}_{4} /$ ethanol-injured livers, (e and f) C. comosum extract $+\mathrm{CCl}_{4} /$ ethanol treated livers

In this study, $\mathrm{CCl}_{4} /$ ethanol-treated rats showed a significant decrease in body weight as well as significant increase in RLW compared to control. These results are in agreement with those reported previously by Soni et al. [40]. Furthermore, a significant increase in RKW was shown. Such 
Table 4: Liver fibrosis scoring, collagen $\%$ and collagen area in different groups

\begin{tabular}{|c|c|c|c|c|c|c|c|}
\hline \multirow[t]{2}{*}{ Groups } & \multicolumn{5}{|c|}{ Fibrosis grade } & \multirow[t]{2}{*}{ Collagen $\%$} & \multirow[t]{2}{*}{ Collagen area $\mu \mathrm{m}^{2}$} \\
\hline & (0) & (1) & (2) & (3) & (4) & & \\
\hline (I) Control & 6 & 0 & 0 & 0 & 0 & 0.91 & $108.84 \pm 31.56$ \\
\hline (III) $\mathrm{CCl}_{4} /$ ethanol & 0 & 0 & 1 & 2 & 3 & 11.02 & $1309.3 \pm 537.26^{\mathrm{a}}$ \\
\hline (IV) C. comosum $+\mathrm{CCl}_{4} /$ ethanol & 3 & 2 & 1 & 0 & 0 & 2.21 & $263.52 \pm 49.44^{\mathrm{b}}$ \\
\hline
\end{tabular}

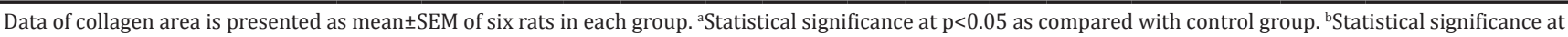
$\mathrm{p}<0.05$ as compared with $\mathrm{CCl}_{4} /$ ethanol group. C. comosum: Calligonum comosum

Table 5: Effect of $C$. comosum extract on $\mathrm{CCl}_{4} /$ ethanol-induced histopathological alterations in kidney

\begin{tabular}{|c|c|c|c|c|c|}
\hline Groups & Glomerular atrophy & $\begin{array}{l}\text { Tubular } \\
\text { degeneration }\end{array}$ & Epithelium necrosis & Interstitial edema & Capillary congestion \\
\hline (I) Control & $*$ & $*$ & $*$ & $*$ & $*$ \\
\hline (II) C. comosum & $*$ & $*$ & $*$ & $*$ & $*$ \\
\hline (III) $\mathrm{CCl} 4 /$ ethanol & +++ & +++ & +++ & +++ & +++ \\
\hline (IV) C. comosum+CCl4/ethanol & $*$ & $*$ & $*$ & $*$ & $*$ \\
\hline
\end{tabular}

(*): Normal; (+++): Severe changes. C. comosum: Calligonum comosum

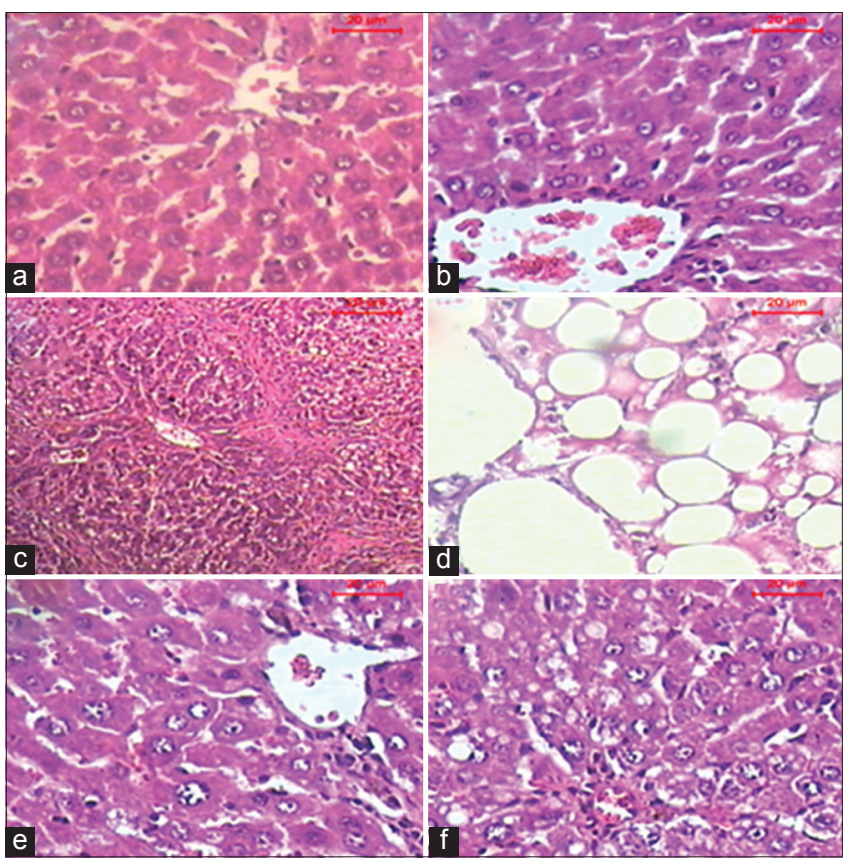

Fig. 7: H \& E staining of rat liver sections; (a and b) control and $C$. comosum extract group shows normal architecture of a hepatic lobule, (c): $\mathrm{CCl}_{4} /$ ethanol group shows the presence of dissection nodules and fibrous septa with effacement of the lobular architecture, (d): $\mathrm{CCl}_{4}$ /ethanol group shows fatty degeneration. Notice the large vacuoles within the liver cells which occupy a large proportion of the cell's volume and push the cytoplasm up against the cell membrane, forming "signet ring cells;"

(e): ( $C$. comosum extract $+\mathrm{CCl}_{4} /$ ethanol) group shows normal architecture of a hepatic lobule and hepatocytes; (f): ( $C$. comosum extract $+\mathrm{CCl}_{4} /$ ethanol) group shows some necrotic hepatocytes and fatty changes (Scale Bar: $20 \mu \mathrm{m}$ )

changes in body weight, RLW and RKW could be attributed to $\mathrm{CCl}_{4}$ toxic effect. An increase in body weight as well as a decrease in liver weight, kidney weight, RLW and RKW was observed by $C$. comosum extract pretreatment.

Serum AST, ALT, and ALP are the most sensitive markers employed in the diagnosis of hepatic damage [41]. In this study, the hepatic damage produced by $\mathrm{CCl}_{4}$ /ethanol treatment was evident by an elevation in the serum marker enzymes as compared to control. This elevation was

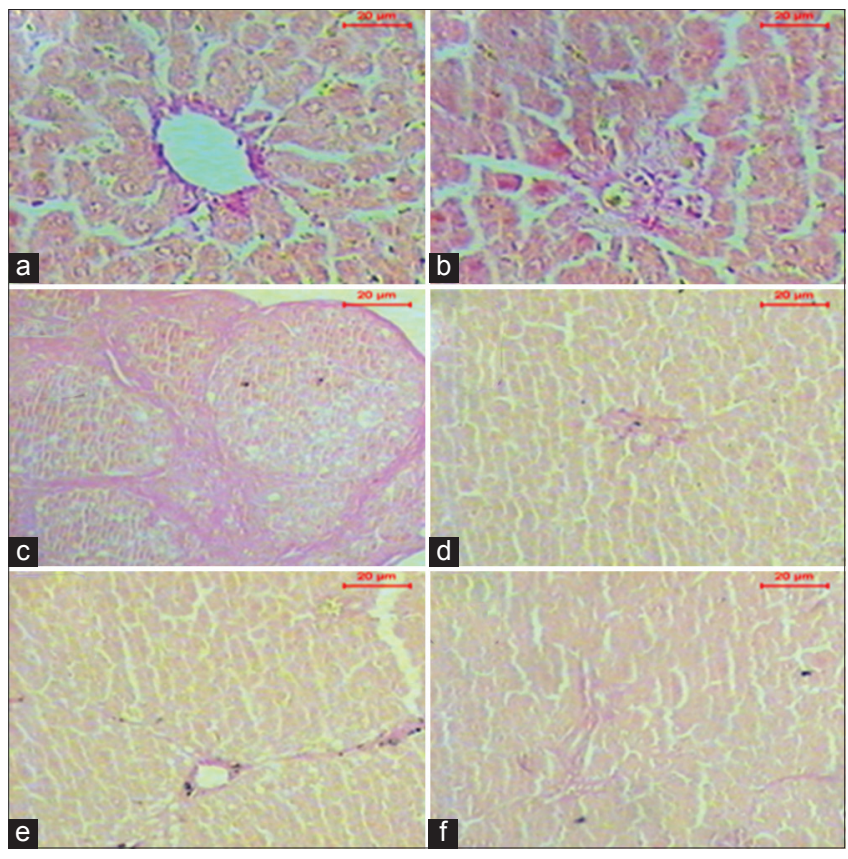

Fig. 8: VG staining of rat liver sections. ( $a$ and $b$ ) Control rats showing normal distribution of collagen deposition in the hepatic lobule and in the portal area respectively;

(c): $\mathrm{CCl}_{4} /$ ethanol group showing a progress increase in collagen accumulation, with portal-portal fibrous septa surrounding the hepatic lobules; ( $d$ and e) $(C$. comosum extract $+\mathrm{CCl}_{4} /$ ethanol) group showing complete disappearance or marked reduction in septal collagen deposition respectively;

(f): $C$. comosum extract group shows normal distribution of collagen deposition in the hepatic lobule and portal area (Micron bar: $20 \mu \mathrm{m}$ )

attributed to the leakage of enzymes from cells into the circulatory system due to altered permeability and loss of functional integrity of liver membrane as a result of severe hepatic injury [42,43]. The results obtained in this work are similar to findings of Biswas et al. [44]. $\mathrm{CCl}_{4}$ undergoes reductive metabolism by the hepatic cytochrome $\mathrm{P} 450$ into a highly reactive ${ }^{+} \mathrm{CCl}_{3}$, which is converted into peroxyl radical $\left({ }^{+} \mathrm{OOCCl}_{3}\right)$ in the presence of oxygen [45]. These activated radicals induced peroxidative degradation of membrane lipids of endoplasmic reticulum rich in polysaturated fatty acids leads to the formation of lipid peroxides that cause damage to the membrane and alter cellular 


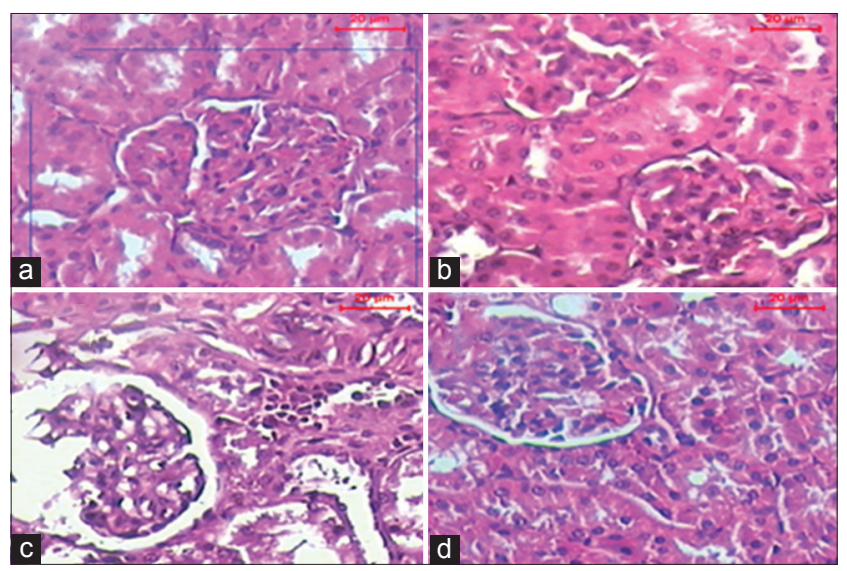

Fig. 9: Photomicrographs of kidney sections. (a and b) Control and $C$. comosum extract groups showing normal architecture of glomeruli, tubules and capillaries;

(c): $\mathrm{CCl}_{4} /$ ethanol injured rat shows glomerular atrophy, tubular degeneration, epithelium necrosis of the tubules, interstitial

edema and congestion in capillary loops, $(\mathrm{d})$ : $(C$. comosum extract $+\mathrm{CCl}_{4} /$ ethanol) group showing normal histological form of the kidney (HE, Scale Bar: $20 \mu \mathrm{m}$ )

function [46]. Pretreatment with C. comosum extract significantly attenuated the elevated activities of serum marker enzymes. This indicates that $C$. comosum extract preserved the structural integrity of the liver cell membrane due to its phytochemical phenolics. Yin et al. [47] demonstrated that phytochemical phenolic compounds restore the functional integrity of the hepatocytes membrane by acting against free radical mediated damages, consequently improve liver injury induced by $\mathrm{CCl}_{4}$.

Total bilirubin level was elevated in $\mathrm{CCl}_{4} /$ ethanol treated rats, possibly as a result of increased production, decreased uptake by the liver or decreased conjugation [48]. However, serum bilirubin level was significantly reduced by $C$. comosum extract pretreatment which is indicative of reversal of liver damage by the extract.

Diminution of serum proteins and albumin levels induced by $\mathrm{CCl}_{4}$ is a further indication of hepatocellular injury $[49,50]$. The results of this study demonstrated that $\mathrm{CCl}_{4} /$ ethanol administration significantly decreased serum levels of total protein and albumin. Pattanayak and Priyashree [51] attributed these reductions to the initial damage in the endoplasmic reticulum by $\mathrm{CCl}_{4}$ activated radicals which impairs the synthetic capacity of the liver that results in decreasing the protein synthesis. On the other hand, serum protein and albumin levels significantly restored near normal by $C$. comosum extract suggesting the hepatoprotective effect of the extract against the deleterious effects of $\mathrm{CCl}_{4}$ on the liver. This hepatoprotective effect may be attributed to the presence of polyphenol in the extract and their membrane stabilizing activity $[52,53]$. Thus, $C$. comosum extract improved the decline in liver synthetic function caused by $\mathrm{CCl}_{4}$. Stimulation of protein synthesis has been regarded as a contributory hepatoprotective mechanism which enhances the regeneration process and the production of liver cells [54]. There was a significant decline in the $\mathrm{A} / \mathrm{G}$ ratio in $\mathrm{CCl}_{4} /$ ethanol group as compared to control. This result is in agreement with Andritoiu et al. [55]. An improvement of the $\mathrm{A} / \mathrm{G}$ ratio revealed in rats pretreated with $C$. comosum extract was due to an increase of serum albumin with a relative decrease of the globulin values.

Administration of $\mathrm{CCl}_{4}$ causes nephrotoxicity as indicated by a significant elevation in serum level of urea and creatinine. From this study, it is evident that elevation in serum urea and creatinine levels in $\mathrm{CCl}_{4} /$ ethanol intoxicated rats can be attributed to the damage of nephron structural integrity; this result is in agreement with Khan and Siddique [56]. On other hand, pretreatment with C. comosum extract significantly reduced the elevation in serum urea and creatinine levels, indicating its protective effect.

The depression of liver microsomal G-6-pase activity, which is a marker of endoplasmic reticulum membrane integrity, is one of the early features of $\mathrm{CC}_{4}$ intoxication [57]. A significant decline in G-6-pase activity was shown in $\mathrm{CCl}_{4} /$ ethanol intoxicated rats compared to control group. Loss of G-6-pase activity has been reported during increased lipid peroxidation [58]. Pretreatment with $C$. comosum extract significantly elevated the activity level of G-6-pase by improving the structural integrity of the hepatocyte endoplasmic reticulum membrane.

A significant decrease in hepatic protein content was also observed in $\mathrm{CCl}_{4} /$ ethanol-treated rats compared to the control group. Such decrease in protein content following administration of $\mathrm{CCl}_{4}$ may be due to defects in protein biosynthesis as well as disruption and disassociation of polyribosomes from endoplasmic reticulum [59]. C. comosum extract pretreatment attenuated the decreased hepatic protein level.

Oxidation of protein's side chains by ROS generates carbonyl moieties that is identified as an early marker of ROS-mediated protein oxidation and is used as a measure of protein damage [60]. The accumulation of oxidized proteins may be an early indication of $\mathrm{CCl}_{4}$ induced liver damage [61]. The hepatic level of protein carbonyl in $\mathrm{CCl}_{4} /$ ethanoltreated group was significantly increased compared to that in the control group but was significantly decreased in C. comosum extract pretreated group, suggesting an antioxidant protection against protein oxidation.

The major cellular mechanisms involved in $\mathrm{CCl}_{4}$ hepatotoxicity are the increase in free-radical production and lipid peroxidation [62]. MDA is one of the main lipid peroxidation products, which was assessed as an indicator of lipid peroxidation in oxidative liver damage [63]. Saad et al. [62] have reported a close relationship between lipid peroxidation and fibrogenesis in $\mathrm{CCl}_{4}$ treated rats. $\mathrm{CCl}_{4} /$ ethanol intoxicated rats showed a significant increase in MDA level in comparison to control group. Our finding revealed that pre-administered C. comosum extract significantly inhibited the increase of liver MDA level. The decrease in MDA level suggested the ameliorative effect of $C$. comosum extract on liver fibrosis induced by $\mathrm{CCl}_{4} /$ ethanol treatment.

Biological systems are supported with various defense mechanisms against environmental and internal stresses [64]. Antioxidant enzymes (such as CAT, SOD, GSH-Px, and GST) are the endogenous first line of defense against damage by oxidative stress. They are actively involved in scavenging of free radicals to maintain the steady state level and consequently integrity and functionality of cells $[65,66]$. GSH, the main non-enzymatic antioxidant participates directly in the neutralization of free radicals and ROS [67]. In this study, $\mathrm{CCl}_{4} /$ ethanol treatment significantly reduced the total content of GSH, as well as the hepatic activity levels of antioxidant enzymes, GSH-Px, GST, CAT, and SOD. Our results are in agreement with Al-Dalaen et al. [68]. Pretreatment with $C$. comosum extract significantly increased the GSH content, GSHPx, GST, CAT, and SOD activity levels. Thus, C. comosum extract exerts its hepatoprotective effect via increasing activity of endogenous antioxidant defense system possibly due to its free radical scavenging activity. El-Sayed et al. [69] reported that during periods of increased oxidative stress, supplementation with exogenous antioxidants increases the antioxidant defense system activity by stimulating synthesis of antioxidant enzymes.

Liver fibrosis also characterized by excess accumulation of collagen-rich extracellular matrix (ECM), which destroys normal liver architecture and finally leads to cirrhosis. At first sight, MMPs, enzymes degrade such fibrillar collagens, might be expected to be under-expressed in fibrosis. However, a number of studies have confirmed that $\mathrm{CCl}_{4}$ may lead to hepatic fibrosis through upregulating the expressions of some MMPs [70,71]. Arthur and Baranova et al. [72,73] reported that MMP-2 increases during liver injury and contribute to liver fibrogenesis. In Agreement with previous data [72,74], we showed that fibrotic rats 
had a significant increase in hepatic MMP-2 activity, whereas it is hardly detectable in normal livers. Planagumà et al. and Han $[75,76]$ suggested that in response to various hepatic toxins liver starts an immense production of cytokines and growth factors, which induce MMPs expression by hepatic stellate cells (HSCs), including MMP-2. MMP-2 promotes transdifferentiation of inactive HSCs through degrading the normal ECM. Activated HSCs have the ability to synthesize collagen I, which in turn stimulates extra MMP-2 activation, thereby amplifying the transdifferentiation process and finally leading to liver fibrosis. C. comosum extract pretreatement significantly reduced hepatic MMP-2 gelatinolytic activity in $\mathrm{CCl}_{4}$ /ethanol-treated rats. Thereby, C. comosum extract can reduce liver fibrosis by inhibiting MMP-2 levels.

\section{CONCLUSION}

It could be concluded that the phytochemical screening of $C$. comosum extract confirmed the presence of antioxidant compounds such as flavonoids and phenolic acids. The significant antioxidant activity of these compounds may contribute to the protection of the hepatic cells against $\mathrm{CCl}_{4}$-induced hepatic oxidative damage. Our results suggest that the methanolic extract of $C$. comosum shoots attenuates the fibrogenesis through its ability to stabilize cell membranes by scavenging free radicals, and consequently, avoid the propagation of lipid peroxide. Hence, the mechanism of $C$. comosum extract hepatoprotection may be due to its antioxidant activity. However, further studies are needed to better understand the mechanism of action of the C. comosum shoots' methanolic extract.

\section{ACKNOWLEDGMENTS}

The authors gratefully acknowledge the contributions of Dr. Abd Elsamed Ibrahim Elshamy (Chemistry of Natural Compounds Department, National Research Centre, Egypt) for extracting and isolating the chemical constituents in the methanolic extract of C. comosum shoots and identifying such isolated compounds, and Prof Dr. Abdel-Razik Hussein Farrag (Pathology Department, National Research Centre, Egypt) for investigating and interpreting histopathological photomicrographs.

\section{REFERENCES}

1. Elpek GÖ. Cellular and molecular mechanisms in the pathogenesis of liver fibrosis: An update. World J Gastroenterol 2014;20(23):7260-76.

2. Hwang TL, Chen CY. Gender different response to immunonutrition in liver cirrhosis with sepsis in rats. Nutrients 2012;4(3):231-42.

3. Hsu YW, Tsai CF, Chuang WC, Chen WK, Ho YC, Lu FJ. Protective effects of silica hydride against carbon tetrachloride-induced hepatotoxicity in mice. Food Chem Toxicol 2010;48(6):1644-53.

4. Fahmy SR, Hamdi SA. Antioxidant effect of the Egyptian fresh water Procambarus clarkii extract in rat liver and erythrocytes. Afr J Pharm Pharmacol 2011;5(6):776-85.

5. Patel M, Verma, RJ. Eclipta alba ameliorates carbon tetrachlorideinduced lipid peroxidation: An in vitro study. Int J Pharm Biol Sci 2013;4(4):877-84.

6. Hashemi JM. Hibiscus sabdariffa calyx extract alleviate hepatotoxicity induced by carbon tetrachloride on male albino rats. Nat Sci 2014;12(4):111-20.

7. Wang Y, Cheng M, Zhang B, Nie F, Jiang H. Dietary supplementation of blueberry juice enhances hepatic expression of metallothionein and attenuates liver fibrosis in rats. PLoS One 2013;8(3):e58659.

8. Ibrahim M, Anjum A, Waheed MA. Curative effect of extracts of sapindus mukorossi and Rheum emodi in $\mathrm{CCl}_{4}$ induced liver cirrhosis in male rats. Glob J Med Res 2012;12(8):47-52.

9. Khan A, Khan RA, Ahmed M, Mushtaq N. In vitro antioxidant, antifungal and cytotoxic activity of methanolic extract of Calligonum polygonoides. Bangladesh J Pharmacol 2015;10(2):316-20.

10. Al-Otaibi M. Aspects of the autecology of Arta (Calligonum comosum L. Her) a medical plant from arid region of Saudi Arabia. J Biodivers Environ Sci 2015;6(3):248-55.

11. ZCHRTM. General authority for health services for the Emirate of Abu Dhabi. Encyclopedia of Medicinal Plants of UAE. Vol. 1. Abu Dhabi, UAE: ZCHRTM; 2005. p. 21.

12. Chouikh A, Mekki M, Adjal EH. Effects of extraction methods on antibacterial activity of different extracts of Calligonum comosum L'her growing in Sahara Algerian. Int J Recent Sci Res 2015;6(4):3534-6.

13. Abdallah HM, Asaad GF, Arbid MS, Abdel-Sattar EA. Antiinflammatory, antinociceptive, antipyretic and gastroprotective effects of Calligonum comosum in rats and mice. Int J Toxicol Pharmacol Res 2014;6(2):26-33

14. Badria FA, Ameen M, Akl MR. Evaluation of cytotoxic compounds from Calligonum comosum L. Growing in Egypt. Z Naturforsch C 2007;62(9-10):656-60.

15. Abdel-Sattar EA, Mouneir SM, Asaad GF, Abdallah HM. Protective effect of Calligonum comosum on haloperidol-induced oxidative stress in rat. Toxicol Ind Health 2014;30(2):147-53.

16. Abdo W, Hirata A, Shukry M, Kamal T, Abdel-Sattar E, Mahrous E, et al. Calligonum comosum extract inhibits diethylnitrosamine-induced hepatocarcinogenesis in rats. Oncol Lett 2015;10(2):716-22.

17. Dawang ND, Datup A. Screening of five medicinal plants for treatment of typhoid fever and gastroenteritis in central Nigeria. Glob Eng Technol Rev 2012;2(9):1-5.

18. Mythili T, Ravindhran R. Phytochemical screening and antimicrobial activity of Sesbaniasesban (L.) Merr. Asian J Pharm Clin Res 2012;5(4):179-82

19. Elshamy AI, El-Gendy A, Farrag AH, Nassar MI. Antidiabetic and antioxidant activities of phenolic extracts of Conyza dioscoridis L. Shoots. Int J Pharm Pharm Sci 2015;7(9):65-72.

20. Chinedu E, Arome D, Ameh FS. A new method for determining acute toxicity in animal models. Toxicol Int 2013;20(3):224-6.

21. Chae HB, Jang LC, Park SM, Son BR, Sung R, Choi JW. An experimental model of hepatic fibrosis induced by alcohol and CCl4: Can the lipopolysaccharide prevent liver injury induced by alcohol and CCl4?. Taehan Kan Hakhoe Chi 2002;8(2):173-8

22. Swanson MA. Glucose-6-phosphatasefrom liver. Methods in Enzymology. Vol. II. New York: Academic Press; 1955. p. 541-4.

23. Evans P, Lyras L, Halliwell B. Measurement of protein carbonyls in human brain tissue. Methods Enzymol 1999;300:145-56

24. Lef'evre G, Beljean-Leymarie M, Beyerle F, Bonnefont-Rousselot D, Cristol JP, Thérond $\mathrm{P}$, et al. Evaluation of lipid peroxidation by measuring thiobarbituric acid reactive substances. Ann Biol Clin 1998;56(3):305-19.

25. Beutler E, Duron O, Kelly BM. Improved method for the determination of blood glutathione. J Lab Clin Med 1963;61:882-8.

26. Necheles TF, Boles TA, Allen DM. Erythrocyte glutathione peroxidase deficiency and hemolytic disease of the newborn infant. J Pediatr $1968 ; 72: 319-24$

27. Habig WH, Pabst MJ, Jakoby WB. Glutathione S-transferases. The first enzymatic step in mercapturic acid formation. J Biol Chem 1974;249(22):7130-9.

28. Aebi H. Catalase in vitro. Methods Enzymol 1984;105:121-6.

29. Minami M, Yoshikawa M. A simplified assay method of superoxide dismutase activity for clinical use. Clin Chim Acta 1979;92(3):337-42.

30. Lowry OH, Rosebrough NJ, Farr AL, Randall RJ. Protein measurement with the Folin phenol reagent. J Biol Chem 1951;193(1):265-75.

31. Toth M, Sohail A, Fridman R. Assessment of gelatinases (MMP-2 and MMP-9) by gelatin zymography. Methods Mol Biol 2012;878:121-35.

32. Drury RA, Wallington EA. Preparation and fixation of tissues. In: Drury R, Wallington E, editors. Carleton's Histological Technique. $5^{\text {th }}$ ed. Oxford: Oxford University Press; 1980.

33. Lee UE, Friedman SL. Mechanisms of hepatic fibrogenesis. Best Pract Res Clin Gastroenterol 2011;25(2):195-206.

34. Friedman SL. Liver fibrosis in 2012: Convergent pathways that cause hepatic fibrosis in NASH. Nat Rev Gastroenterol Hepatol 2013;10(2):71-2.

35. Al-Rasheed NM, Attia HA, Mohamad RA, Al-Rasheed NM, Al-Amin MA, Al-Onazi A. Aqueous date flesh or pits extract attenuates liver fibrosis via suppression of hepatic stellate cell activation and reduction of inflammatory cytokines, transforming growth factor- $\beta 1$ and angiogenic markers in carbon tetrachloride-intoxicated rats. Evid Based Complement Alternat Med 2015;2015:247357.

36. Bataller R, Rombouts K, Altamirano J, Marra F. Fibrosis in alcoholic and nonalcoholic steatohepatitis. Best Pract Res Clin Gastroenterol 2011;25(2):231-44.

37. Dias JV, Paredes BD, Mesquita LF, Carvalho AB, Kozlowski EO, Lessa AS, et al. An ultrasound and histomorphological analysis of experimental liver cirrhosis in rats. Braz J Med Biol Res 2008;41(11):992-9.

38. Safer AM, Afzal M, Hanafy N, Mousa S. Green tea extract therapy diminishes hepatic fibrosis mediated by dual exposure to carbon tetrachloride and ethanol: A histopathological study. Exp Ther Med 
2015;9(3):787-94

39. Hong M, Li S, Tan HY, Wang N, Tsao SW, Feng Y. Current status of herbal medicines in chronic liver disease therapy: The biological effects, molecular targets and future prospects. Int $\mathrm{J}$ Mol Sci 2015;16(12):28705-45

40. Soni B, Visavadiya NP, Madamwar D. Ameliorative action of cyanobacterial phycoerythrin on $\mathrm{CCl}(4)$-induced toxicity in rats. Toxicology 2008;248(1):59-65.

41. Palaniswamy R, Raghunathan PP. Protective effect of Bacopa monnieri leaf extract against oxidative stress induced hepatotoxicity in rats. Int J Pharm Pharm Sci 2013;5(3):555-8.

42. Ramakrishna S, Geetha KM, Bhaskargopal PV, Kumar RP, Madav CP, Umachandar L. Effect of Mallotus philippensis Muell. Arg leaves against hepatotoxicity of carbon tetrachloride in rats. Int J Pharm Sci Res 2011;2(2):74-83.

43. Firdous SM, Sravanthi K, Debnath R, Neeraja KJ. Protective effect of ethanolic extract and its ethyl acetate and n-butanol fractions of Sechium edule fruits against carbon tetrachloride induced hepatic injury rats. Int J Pharm Pharm Sci 2012;4(1):35-49.

44. Biswas D, Gouda ST, Gouda TS, Gowrishankar NL. In vitro antioxidant and in vivo hepatoprotective activity of ethanol extracts from the bark of Shorea robusta (Dipterocarpaceae) against carbon tetra chlorideinduced liver toxicity in rats. Asian J Pharm Clin Res 2016;9(6):225-9.

45. Heibatollah S, Reza NM, Izadpanah G, Sohailla S. Hepatoprotective effect of Cichorium intybus on $\mathrm{CCl}_{4}$-induced liver damage in rats. Afr J Biochem Res 2008;2(6):141-4.

46. Saif A, Sarhan O, Elmogy M, Mutwally H. Hepatoprotective effects of zamzam water against carbon tetrachloride induced liver damage in rats: Biochemical, histopathological, and molecular evidences. Life Sci J 2014;11(10):300-8

47. Yin G, Cao L, Xu P, Jeney G, Nakao M. Hepatoprotective and antioxidant effects of Hibiscus sabdariffa extract against carbon tetrachloride-induced hepatocyte damage in Cyprinus carpio. In vitro Cell Dev Biol Anim 2011;47:10-5.

48. Zameer M, Rauf A, Qasmi IA. Hepatoprotective activity of a Unani polyherbal formulation "kabideen" in $\mathrm{CCl}_{4}$ induced liver toxicity in rats. Int J Appl Biol Pharm Technol 2015;6(1):8-16.

49. Eidi A, Mortazavi P, Tehrani ME, Rohani AH, Safi SB. Hepatoprotective effects of pantothenic acid on carbon tetrachloride-induced toxicity in rats. Exp Clin Sci Int Online J 2012;11:748-59.

50. Hassan SW, Tillo MK, Lawal M, Umar RA, Ndakotsu MA, Faroukand UZ, et al. Hepatoprotective action of stem bark extracts of Newbouldia laevis in rats treated with carbon tetrachloride $\left(\mathrm{CCl}_{4}\right)$. J Global Biosci 2015;4(3):1627-46

51. Pattanayak SP, Priyashree S. Hepatoprotective activity of the leaf extracts from Dendrophthoe falcate (Lf) Ettingsh against carbon tetrachloride induced toxicity in wistar albino rates. Pharmacogn Mag 2008;4:218-22.

52. Palanivel MG, Rajkapoor B, Kumar RS, Einstein JW, Kumar EP, Kumar MR, et al. Hepatoprotective and antioxidant effects of Pisonia aculeate L. Against $\mathrm{CCl}_{4}$-induced hepatic damage in rats. Sci Pharm 2008;76:203-15.

53. Chavan SD, Patil SB, Naikwade NS. Biochemical and histopathological studies of Butea monosperma (Lam) Taub leaves on paracetamolinduced hepatotoxicity in albino rats. J Pharm Res 2012;5:4006-8.

54. Fahmy SR. Anti-fibrotic effect of Holothuria arenicola extract against bile duct ligation in rats. BMC Complement Altern Med 2015;15:14.

55. Andritoiu CV, Lacramioara O, Vasile A, Marcel P. Effect of apitherapy formulations against carbon tetrachloride-induced toxicity wistar rats after three weeks of treatment. Molecules 2014;19(9):13374-91.

56. Khan MR, Siddique F. Antioxidant effects of Citharexylum spinosum in $\mathrm{CCl} 4$ induced nephrotoxicity in rat. Exp Toxicol Pathol 2012;64(4):349-55.

57. Basu S. Carbon tetrachloride-induced hepatotoxicity: A classic model of lipid peroxidation and oxidative stress. In: Basu S, Wiklund L editors.
Studies on Experimental Models, Oxidative stress in Applied Basic Research and Clinical Practice. New York, USA: Human Press; 2011.

58. de Medeiros BJ, Costa KD, Ribeiro JF, Silva JC Jr, Barbosa WR, Carvalho JT. Liver protective activity of a hydroethanolic extract of Arrabidaea chica (Humb. and Bonpl.) B. Verl. (pariri). Pharmacogn Res 2011;3(2):79-84.

59. Alhassan AJ, Sule MS, Atiku MK, Wudil AM, Dangambo MA, Mashi JA, et al. Effect of Calitropis procera aqueous root extract against $\mathrm{CCl} 4$ induced liver toxicity in rabbits. Bayero J Pure Appl Sci 2012;5(1):38-43

60. Doustimotlagh AH, Dehpour AR, Nourbakhsh M, Golestani A. Alteration in membrane protein, antioxidant status and hexokinase activity in erythrocytes of $\mathrm{CCl}_{4}$-induced cirrhotic rats. Acta Med Iran 2014:52(11):795-803.

61. Kamel HH, Abd-El-Rahman HA, Walaa MS, Mohamed AH. Protective effect of some antioxidants against CCl4-induced toxicity in liver cells from BRL3A cell line. J Am Sci 2010;6(10):992-1003.

62. Saad AA, Mokhamer EM, Mohsen MA, Fadaly GA. Attenuation of carbon tetrachloride-induced hepatic fibrosis by glycine, vitamin $\mathrm{E}$ and vitamin C. J Exp Integr Med 2014;4(3):180-6.

63. Yang BY, Zhang XY, Guan SW, Hua ZC. Protective Effect of procyanidin B2 against $\mathrm{CCl}$-induced acute liver injury in mice. Molecules 2015;20(7):12250-65.

64. Jayakumar T, Sakthivel M, Thomas PA, Geraldine P. Pleurotus ostreatus, an oyster mushroom, decreases the oxidative stress induced by carbon tetrachloride in rat kidneys, heart and brain. Chem Biol Interact 2008;176(2-3):108-20.

65. Khan MR, Younus T. Prevention of CCl(4)-induced oxidative damage in adrenal gland by Digera muricata extract in rat. Pak J Pharm Sci 2011;24(4):469-73.

66. Al Anazi AS, Anwar MJ, Ahmad MA. Hepatoprotective and antioxidant activity of Tragiain volucrata root extracts against $\mathrm{CCl}_{4}$ induced hepatotoxicity in rats. Pharm Lett 2015;7(5):146-52.

67. Huang MC, Chen $\mathrm{CH}$, Peng FC, Tang SH, Chen CC. Alterations in oxidative stress status during early alcohol withdrawal in alcoholic patients. J Formos Med Assoc 2009;108(7):560-9

68. Al-Dalaen S, Alzyoud J, Al-Qtaitat A. The effects of L-arginine in modulating liver antioxidant biomarkers within carbon tetrachloride induced hepatotoxicity: Experimental study in rats. Biomed Pharmacol J 2016;9(1):293-8.

69. El-Sayed YS, Lebda MA, Hassinin M, Neoman SA. Chicory (Cichorium intybus L.) root extract regulates the oxidative status and antioxidant gene transcripts in CCl4-induced hepatotoxicity. PLoS One 2015;10(3):e0121549.

70. Peng WH, Tien YC, Huang CY, Huang TH, Liao JC, Kuo CL, et al. Fraxinus rhynchophylla ethanol extract attenuates carbon tetrachlorideinduced liver fibrosis in rats via down-regulating the expressions of uPA, MMP-2, MMP-9 and TIMP-1. J Ethnopharmacol 2010;127(3):606-13.

71. Giannandrea M, Parks WC. Diverse functions of matrix metalloproteinases during fibrosis. Dis Model Mech 2014;7:193-203.

72. Arthur MJ. Fibrogenesis II. Metalloproteinases and their inhibitors in liver fibrosis. Am $\mathrm{J}$ Physiol Gastrointest Liver Physiol 2000;279(2):G245-9

73. Baranova A, Lal P, Birerdinc A, Younossi ZM. Non-invasive markers for hepatic fibrosis. BMC Gastroenterol 2011;11:91.

74. Zhu YK, Wang BE, Shen FJ, Jia JD, Ma H. Dynamic evolution of MMP-2 gene expression and its enzymatic activities in experimental liver fibrosis. Zhonghua Gan Zang Bing Za Zhi 2005;13(7):509-12.

75. Planagumà A, Clària J, Miquel R, López-Parra M, Titos E, Masferrer JL, et al. The selective cyclooxygenase-2 inhibitor SC-236 reduces liver fibrosis by mechanisms involving non-parenchymal cell apoptosis and PPAR $\gamma$ activation. FASEB J 2005;19(9):1120-2.

76. Han YP. Matrix metalloproteinases, the pros and cons, in liver fibrosis. J Gastroenterol Hepatol 2006;21(3):S88-91 